\title{
Sex Steroids, Bone Mass, and Bone Loss \\ A Prospective Study of Pre-, Peri-, and Postmenopausal Women
}

\author{
Charles Slemenda, ${ }^{*}$ Christopher Longcope, ${ }^{\ddagger}$ Munro Peacock, ${ }^{\star}$ Siu Hui, ${ }^{\star}$ and C. Conrad Johnston* \\ $*$ Department of Medicine, Indiana University School of Medicine, Indianapolis, Indiana 46202; and ${ }^{\ddagger}$ Departments of Medicine, and \\ Obstetrics and Gynecology, University of Massachusetts, Worcester, Massachusetts 01605
}

\begin{abstract}
Although bone loss around the time of menopause is driven by estrogen deficiency, the roles of estrogens and androgens in the preservation of skeletal mass at other stages of life are less well understood. To address this issue we studied 231 women between the ages of 32 and 77 with multiple measurements of sex steroids and bone mass over a period of 2-8 yr. In all women bone mass was negatively associated with concentrations of sex-hormone binding globulin, and positively associated with weight. Bone loss occurred from all skeletal sites in peri- and postmenopausal women, but premenopausal women lost bone only from the hip $(-0.3 \% / \mathrm{yr})$ and had positive rates of change in the radius and spine. Bone loss was significantly associated with lower androgen concentrations in premenopausal women, and with lower estrogens and androgens in peri- and postmenopausal women. Sex steroids are important for the maintenance of skeletal integrity before menopause, and for as long as 20-25 yr afterwards. (J. Clin. Invest. 1996. 97:14-21.) Key words: estrogens $\bullet$ androgens $\bullet$ sex-hormone binding globulin • osteocalcin $\bullet$ menopause
\end{abstract}

\section{Introduction}

The importance of estrogen deficiency in the rapid bone loss around the time of menopause has been recognized for many years $(1,2)$. Studies of younger women with amenorrhea as a result of intense athletic activity (3), anorexia nervosa (4), and other causes (5) have shown that estrogen deficiency at any age may also be associated with bone loss, although many of these conditions are more complicated than simple estrogen deficiency. Moreover, women with late onset of menarche appear to have significantly reduced peak bone mass (6). Among perimenopausal women, serum estrogens are lower among women with more rapid bone loss (7) and serum osteocalcin concentrations as a marker of rates of skeletal turnover, are higher in perimenopausal women with lower estrogen concentrations and more rapid bone loss (7).

Some exceptions to this pattern have been noted. Amenorrheic women with unusually high androgen concentrations ap-

Address correspondence to Charles W. Slemenda, Dept. of Medicine, Indiana University School of Medicine, Riley Hospital for Children, RR 136, 702 Barnhill Drive, Indianapolis, IN 46202. Phone: 317-2742666; FAX: 317-274-2678.

Received for publication 26 June 1995 and accepted in revised form 26 September 1995.

J. Clin. Invest.

(C) The American Society for Clinical Investigation

0021-9738/96/01/0014/08 \$2.00

Volume 97, Number 1, January 1996, 14-21 pear to escape the detrimental skeletal effects of estrogen deficiency (8), as do some elite female athletes with extremely intense levels of weight-bearing activities, including figure skaters (9) and gymnasts (10). There is other evidence of the potential positive role androgens may play in skeletal health in women. Perimenopausal women with higher testosterone concentrations have slower rates of bone loss than those with lower concentrations, independent of their estrogen status (7). Premenopausal women with androgen excess have higher than normal bone mass with or without $(8,11)$ normal menstrual cycling.

Therefore, both estrogens and androgens are important in the extremes, particularly during periods of relative estrogen deficiency. However, less is known regarding the importance of sex steroids in more common circumstances, i.e., in normally cycling premenopausal women and in postmenopausal women after the period of rapid perimenopausal bone loss is complete. Many studies have addressed the associations between bone mass and hormone concentrations (12-14) in both pre- and postmenopausal women, and others have addressed these relationships through indirect associations observed with sex-hormone binding globulin $(12,15)$.

Our studies were designed to address the relationships between sex steroids and bone mass and bone loss in normally cycling premenopausal women and in postmenopausal women without exposure to exogenous hormones. Specifically, we addressed the magnitude of bone loss in pre-, peri-, and postmenopausal women, the possibility that endogenous sex steroids and sex-hormone binding globulin are associated both with bone mass and rates of bone loss during these periods, and the associations between serum osteocalcin and bone mass and loss.

\section{Methods}

Subjects were recruited between 1986 and 1993 for a prospective study of bone mass and endogenous sex steroids primarily through newspaper advertisements. There was no compensation provided for participation. Premenopausal women $(n=94)$ were eligible for study if they were between the ages of 30 and 48 , had follicle-stimulating hormone (FSH) concentrations $<15 \mathrm{mIU}$, and were cycling regularly (mean age $=41.7$, range 32.5-47.9). Premenopausal women who became perimenopausal $(n=11)$ were excluded from these analyses. Women who were pregnant, planning a pregnancy, or taking oral contraceptives or other medications which might affect bone metabolism were ineligible. Women were classified as perimenopausal if they were between the ages of 48 and 59 inclusive, and had FSH concentrations $\geq 15 \mathrm{mIU}$, and were continuing to menstruate $(n=62)$. Those who stopped cycling for $1 \mathrm{yr}$ or more or began taking estrogens $(n=24)$ were excluded from these analyses. Postmenopausal women $(n=75$, mean age $=66.4$, range 60.1-77.1) were eligible if they had experienced their last menstrual period at least $1 \mathrm{yr}$ before and were not taking any medications known to affect the skeleton. Past use of estrogens for $<6$ mo or past or current use of calcium supplements 


\begin{tabular}{|c|c|c|c|}
\hline & \multicolumn{3}{|c|}{ Menopausal status* } \\
\hline & Pre- $(n=96)$ & Peri- $(n=28-62)^{\ddagger}$ & Post- $(n=73)$ \\
\hline \multicolumn{4}{|l|}{$\mathrm{BMD}\left(\mathrm{grams} / \mathrm{cm}^{2}\right)$} \\
\hline FN & $0.84(0.13)$ & $0.78(0.12)$ & $0.67(0.10)$ \\
\hline Trochanter & $0.71(0.11)$ & $0.69(0.10)$ & $0.59(0.09)$ \\
\hline L2-L4 & $1.11(0.15)$ & $1.06(0.15)$ & $0.93(0.15)$ \\
\hline Radius & $0.70(0.05)$ & $0.68(0.06)$ & $0.60(0.08)$ \\
\hline \multicolumn{4}{|c|}{ Change in BMD (grams $/ \mathrm{cm}^{2} / \mathrm{yr}$ ) } \\
\hline FN & $-0.0021(0.013)$ & $-0.0080(0.011)$ & $-0.0085(0.010)$ \\
\hline Trochanter & $-0.0009(0.010)$ & $-0.0048(0.015)$ & $-0.0044(0.010)$ \\
\hline L2-L4 & $+0.0036(0.012)$ & $-0.0034(0.016)$ & $-0.0022(0.016)$ \\
\hline Radius & $+0.0017(0.007)$ & $-0.0121(0.014)$ & $-0.0054(0.008)$ \\
\hline \multicolumn{4}{|l|}{ Sex steroids } \\
\hline $\mathrm{E} 1(\mathrm{pg} / \mathrm{ml})$ & $47.0(14.6)$ & $40.6(16.2)$ & $31.8(7.8)$ \\
\hline $\mathrm{E} 2(\mathrm{pg} / \mathrm{ml})$ & $47.5(18.7)$ & $28.8(17.4)$ & $20.0(4.8)$ \\
\hline $\mathrm{T}(\mathrm{ng} / \mathrm{ml})$ & $0.23(0.10)$ & $0.16(0.09)$ & $0.18(0.11)$ \\
\hline $\mathrm{A}(\mathrm{ng} / \mathrm{ml})$ & $1.13(0.34)$ & $0.62(0.30)$ & $0.66(0.29)$ \\
\hline $\mathrm{P}(\mathrm{ng} / \mathrm{ml})$ & $0.17(0.19)$ & $0.19(0.22)$ & $0.07(0.05)$ \\
\hline DHEA (ng/ml) & $2.20(0.94)$ & $1.61(0.81)$ & $1.02(0.75)$ \\
\hline DHEAS $(\mu \mathrm{g} / \mathrm{ml})$ & $1.60(0.82)$ & $1.25(0.22)$ & $0.77(0.61)$ \\
\hline SHBG (nM/liter) & $63.2(26.9)$ & $60.4(27.1)$ & $54.4(22.3)$ \\
\hline
\end{tabular}

*Premenopause defined as age $<48$ and all FSH measurements $<15$. Perimenopause defined as mean FSH $>15$ and age $<60$. Postmenopause defined as age $>60 .{ }^{*}$ Sample size in perimenopausal women is 28 for lumbar spine and femur BMD data because some women $(n=34)$ were measured on a different densitometer. Sample size is 62 for radius BMD and all other measurements.

were not grounds for exclusion. Women were excluded if they did not meet the arbitrary definitions of pre-, peri-, or postmenopausal $(n=$ 14, e.g., women under age 48 with regular menses but elevated FSH).

Bone mineral density $(\mathrm{BMD})^{1}$ measurements of the midshaft radius (R), lumbar spine (SP), and proximal femur (femoral neck [FN], greater trochanter, Wards triangle) were made at 6-mo to 1-yr intervals. Radius measurements were made using single photon absorptiometry (model SP-2; Lunar Corp., Madison, WI); other sites were measured using dual energy x-ray absorptiometry (model 1000W; Hologics Corp., Waltham, MA). Precision errors (coefficient of variation of repeated measurements on individuals) were 1.04\% (lumbar spine) to $2.4 \%$ (trochanter). For all subjects there were at least three measurements (mean $=8.6)$ of BMD at all skeletal sites.

Blood was drawn during the early follicular phase (days 3-7 of the menstrual cycle) for pre- and perimenopausal women on morning samples insofar as possible. Measurements were made, as reported previously (7), for estrone (E1), estradiol (E2), estrone sulfate, progesterone $(\mathrm{P})$, testosterone $(\mathrm{T})$, androstenedione $(\mathrm{A})$, dehydroepiandrosterone (DHEA) and its sulfate (DHEAS), sex-hormone binding globulin (SHBG), and free- (FrE2 and FrT), albumin-, and SHBG-bound E2 and T; the non-SHBG-bound fractions of E2 and T are referred to as NSE2 and NST, respectively. Sex steroids assays were run on batches of 40 samples with six controls (two high, two medium, two low values) added to each batch. Markers of skeletal metabolism were also measured at these same intervals. For the purpose of this study only osteocalcin (OC) is reported.

1. Abbreviations used in this paper: $\mathrm{A}$, androstenedoine; $\mathrm{BMD}$, bone mineral density; DHEA, dehydroepiandrosterone; DHEAS, DHEA sulfate; E1, estrone; E2, estradiol; FN, femoral neck; OC, osteocalcin; $\mathrm{P}$, progesterone; $\mathrm{R}$, midshaft radius; SHBG, sex-hormone binding globulin; SP, lumbar spine; T, testosterone.
Statistical analyses. For each person, at each skeletal site, the mean value of all bone mass measurements was calculated; this is reported as mean BMD (grams $/ \mathrm{cm}^{2}$ ). Next, BMD was regressed on time to yield a rate of change in BMD $\left(\mathrm{grams} / \mathrm{cm}^{2} / \mathrm{yr}\right)$ for each subject over the period of time for which they were studied. Negative slopes indicate bone loss. For sex steroids and OC, identical procedures were used to obtain the mean values and rates of change in each variable over the entire study period for each individual. Thus, there is a within-subject mean $( \pm S D)$ and slope $( \pm S D)$ for each variable that was measured three or more times. Rates of change in the sex steroids and OC were uninformative (i.e., poorly correlated with other variables, with high within-person variances). Patterns of change within subjects were consistent in direction with the cross-sectional except as noted. Thus, the focus of the analysis was on the associations between an individual's mean sex steroid concentrations and her mean BMD or rate of change in BMD during the period when these sex steroids were measured.

The primary questions to be addressed were: $(a)$ whether bone loss occurred before menopause (i.e., whether the group mean slope of BMD over time was significantly negative); $(b)$ whether the individual's mean BMD and prevailing mean sex steroids were associated before, during, and after menopause (i.e., whether the correlations between these variables were significantly different from zero); and (c) whether individuals' rates of change in BMD were associated with their prevailing mean sex steroid concentrations averaged over the period of study. To determine whether there were significant changes in BMD, the slopes were tested against zero. Associations among variables were initially examined with Pearson correlations after logtransformations of markedly non-normally distributed variables (primarily the concentrations of sex steroids). For premenopausal women, associations with bone loss were also tested by comparing those women who lost at least $1 \%$ per year $\left(\right.$ mean $=-0.017 \mathrm{grams} / \mathrm{cm}^{2} / \mathrm{yr}=$ $-2 \% / y r$ ) from the femoral neck (the only site with significant premenopausal bone loss) against all other women (mean rate of change 
in bone mass $=+0.3 \% / y r$ ) ; this analysis was performed to identify factors which might be associated with more rapid premenopausal bone loss (univariate comparison by $t$ test, multivariate by logistic regression).

Regression models were then constructed to predict BMD and changes in BMD from sex steroids, age, weight, and other variables. All of these relationships were examined separately for pre-, peri-, and postmenopausal groups because the large cross-menopausal changes in sex steroids, particularly estrogens, can induce strong associations which may not reflect the activity of estrogens in any single time period.

\section{Results}

Changes in bone mass and sex steroids with age and menopause. The descriptive data are shown in Table I. Premenopausal women (age $<48$ and FSH $<15$ ) had significant bone loss only from the femoral neck $(-0.25 \% / \mathrm{yr},-0.0021$ grams/ $\left.\mathrm{cm}^{2} / \mathrm{yr}\right)$. The radius $\left(+0.24 \% / \mathrm{yr},-0.0017 \mathrm{grams} / \mathrm{cm}^{2} / \mathrm{yr}\right)$ and spine $\left(+0.32 \% / \mathrm{yr}, 0.0036 \mathrm{grams} / \mathrm{cm}^{2} / \mathrm{yr}\right)$ were stable or increasing until near menopause. When analyses were limited to only those women $(n=34)$ with at least $4 \mathrm{yr}$ of follow-up and eight or more measurements, the bone loss from the femoral remained statistically significant $(-0.35 \% / \mathrm{yr},-0.0030$ grams/ $\mathrm{cm}^{2} \mathrm{yr}$ ). Perimenopausal women lost bone from all sites. Postmenopausal women also lost bone from all sites, but the rates of bone loss were generally slower than in the earlier postmenopausal years (Table I). SHBG, E1, E2, T, and A were also stable in premenopausal women, but DHEA and DHEAS showed linear declines $(\sim 2 \% / \mathrm{yr})$ from ages $35-75$. Using either cross-sectional data or longitudinal rates within individual subjects yielded similar results with the exception of SHBG, which was significantly lower among postmenopausal women $(r=-0.19)$, but showed no significant linear trends within individuals in any of the three groups (i.e., pre-, peri-, or postmenopausal). Both estrogens (E1 and E2) and androgens ( $\mathrm{T}$ and $\mathrm{A}$ ) were lower in postmenopausal than premenopausal women.

Univariate associations among sex steroids. Because there are strong associations among the sex steroids, and between sex steroids and SHBG, we next addressed these relationships

Table II. Correlations among Hormones, and Height and Weight, by Menopausal Status

\begin{tabular}{|c|c|c|c|c|c|c|c|c|c|c|}
\hline & $\mathrm{Ht}$ & Wt & E1 & E2 & $\mathrm{P}$ & $\mathrm{T}$ & A & SHBG & DHEA & DHEAS \\
\hline \multicolumn{11}{|c|}{ Premenopausal } \\
\hline Age & -0.05 & 0.08 & $+0.19^{*}$ & 0.15 & $0.18^{*}$ & $-0.18^{*}$ & $-0.28^{\ddagger}$ & 0.04 & $-0.29^{\ddagger}$ & $-0.25^{\ddagger}$ \\
\hline $\mathrm{Ht}$ & & $0.17^{*}$ & -0.01 & -0.03 & 0.05 & -0.13 & -0.15 & 0.14 & -0.14 & -0.15 \\
\hline $\mathrm{Wt}$ & & & 0.07 & $-0.24^{\S}$ & 0.14 & 0.17 & -0.09 & $-0.33^{\ddagger}$ & -0.24 & 0.00 \\
\hline $\mathrm{E} 1$ & & & & $0.71^{\mathscr{\Psi}}$ & 0.16 & 0.11 & 0.08 & $0.35^{\text {II }}$ & 0.01 & 0.00 \\
\hline $\mathrm{E} 2$ & & & & & 0.02 & -0.13 & -0.01 & $0.52^{\pi}$ & 0.06 & -0.10 \\
\hline $\mathrm{P}$ & & & & & & 0.00 & -0.09 & -0.04 & -0.10 & 0.07 \\
\hline $\mathrm{T}$ & & & & & & & $-0.65^{\mathbb{\pi}}$ & -0.16 & $0.52^{\mathscr{\Psi}}$ & $0.59^{\pi}$ \\
\hline A & & & & & & & & 0.02 & $0.66^{\mathrm{II}}$ & $0.67^{\mathbb{I}}$ \\
\hline SHBG & & & & & & & & & 0.12 & -0.16 \\
\hline DHEA & & & & & & & & & & $0.71^{\mathbb{\pi}}$ \\
\hline \multicolumn{11}{|c|}{ Perimenopausal } \\
\hline Age & 0.13 & 0.21 & $-0.25^{\S}$ & $-0.54^{\Uparrow}$ & -0.23 & $-0.25^{\S}$ & $-0.41^{\mathbb{\pi}}$ & -0.06 & $-0.29^{\ddagger}$ & $-0.29^{\ddagger}$ \\
\hline $\mathrm{Ht}$ & & $0.53^{\text {I }}$ & -0.17 & -0.19 & $-0.35^{\S}$ & 0.09 & -0.07 & -0.26 & -0.16 & 0.19 \\
\hline $\mathrm{Wt}$ & & & -0.03 & -0.15 & 0.00 & 0.17 & -0.13 & $-0.60^{\pi}$ & -0.19 & -0.03 \\
\hline E1 & & & & $0.64^{\pi}$ & $0.51^{\text {ฯ }}$ & $0.31^{\ddagger}$ & 0.45 & 0.14 & $0.42^{\mathbb{q}}$ & $0.38^{\pi}$ \\
\hline $\mathrm{E} 2$ & & & & & $0.44^{\pi}$ & $0.27^{\S}$ & $0.37^{\S}$ & 0.20 & $0.31^{\ddagger}$ & $0.28^{\S}$ \\
\hline $\mathrm{P}$ & & & & & & 0.09 & 0.07 & -0.12 & 0.15 & 0.15 \\
\hline $\mathrm{T}$ & & & & & & & $0.60^{\pi}$ & -0.03 & $0.45^{\mathrm{I}}$ & $0.42^{\pi}$ \\
\hline A & & & & & & & & 0.02 & $0.67^{\text {II }}$ & $0.60^{\mathbb{4}}$ \\
\hline SHBG & & & & & & & & & 0.04 & 0.02 \\
\hline DHEA & & & & & & & & & & $0.76^{\mathbb{\pi}}$ \\
\hline \multicolumn{11}{|c|}{ Postmenopausal } \\
\hline Age & -0.40 & -0.03 & 0.02 & -0.01 & -0.15 & 0.10 & 0.15 & -0.07 & -0.16 & -0.12 \\
\hline $\mathrm{Ht}$ & & 0.07 & 0.03 & 0.01 & 0.18 & 0.00 & 0.00 & 0.11 & 0.02 & -0.06 \\
\hline Wt & & & $0.40^{\mathbb{\pi}}$ & $0.43^{\ddagger}$ & 0.01 & 0.16 & 0.14 & $-0.53^{\pi}$ & -0.03 & 0.01 \\
\hline E1 & & & & $0.31^{\ddagger}$ & $0.34^{\ddagger}$ & $0.38^{\mathbb{I}}$ & $0.37^{\pi}$ & $-0.50^{\llbracket}$ & $0.29^{\ddagger}$ & $0.27^{\ddagger}$ \\
\hline E2 & & & & & 0.03 & 0.15 & 0.08 & $-0.29^{\ddagger}$ & -0.18 & -0.17 \\
\hline $\mathrm{P}$ & & & & & & 0.07 & -0.06 & -0.12 & $0.20 *$ & 0.18 \\
\hline $\mathrm{T}$ & & & & & & & $0.76^{\mathrm{II}}$ & $-0.20 *$ & 0.48 & $0.51^{\pi}$ \\
\hline A & & & & & & & & $-0.20 *$ & $0.68^{\mathrm{qI}}$ & $0.63^{\mathbb{I}}$ \\
\hline SHBG & & & & & & & & & -0.07 & -0.09 \\
\hline DHEA & & & & & & & & & & $0.82^{\pi}$ \\
\hline
\end{tabular}

All analyses were done using the within-subject mean hormone concentrations, mean height, weight, and age over the entire period of study. ${ }^{*} 0.05<P<0.10 ;{ }^{\S} P<0.05 ;{ }^{*} P<0.01$; and ${ }^{\mathbb{T}} P<0.001$. 
(Table II). The expected strong positive correlations between $\mathrm{E} 1$ and $\mathrm{E} 2$ and between $\mathrm{T}$ and $\mathrm{A}$ were seen in all three groups. SHBG was negatively correlated with weight $(-0.60<r<$ -0.33 ) in all groups. However, the correlations between SHBG and the estrogens differed depending on menopausal status. SHBG was significantly higher in premenopausal women with higher E1 $(r=+0.35)$ and E2 $(r=+0.52)$ concentrations, but significantly lower in postmenopausal women with higher E1 $(r=-0.50)$ and E2 $(r=-0.29)$ concentrations. In premenopausal women there was a negative correlation between SHBG and unbound T ( $r=-0.41, P<0.0001)$, but a positive correlation between SHBG and unbound E2 $(r=$ $+0.26, P=0.01$ ).

Univariate associations, sex steroids with bone mass. The correlations between BMD (Table III) and body size and sex steroids are shown separately for the pre-, peri-, and postmenopausal groups. BMD at all sites was associated positively with weight and negatively with SHBG concentrations, although these correlations varied slightly with menopausal status. Among peri- and postmenopausal women BMD was positively correlated with either E1 or E2, depending on skeletal site, but no similar associations were seen for the premenopausal group. Combining all women studied, after adjustment for age, BMD at all sites was higher among those with greater weights $(0.29<r<0.39, P<0.0001)$ and lower in those with greater SHBG concentrations $(-0.33<r<-0.17,0.0001<$ $P<0.05$ ); there were also significant positive correlations between unbound $\mathrm{T}$ and BMD at the spine and hip. Regression models including weight, SHBG, and menopausal status accounted for between 36 and $41 \%$ of the variability in BMD, depending on skeletal site.

Univariate associations with changes in $B M D$. The correlations with bone loss (Table IV) were weaker, although perimenopausal bone loss from the radius was slower in those with higher estrogens and androgens, and more rapid in those with higher OC concentrations, as we have reported previously (7). Among postmenopausal women bone loss from the hip was slower among those with greater weight gains and higher unbound testosterone concentrations. In these same women, bone loss from the spine and radius was slower in those with higher estrogens.

Premenopausal bone loss. Because rates of bone loss in these younger women were very small, we examined the possibility that there was a subgroup with greater rates of bone loss where associations with sex steroids might be clearer than in the larger sample. To determine whether those who lost greater amounts of femoral neck BMD before menopause differed from those who did not, premenopausal women who lost at least $1 \% / \mathrm{yr}$ (mean change $=-0.017 \mathrm{grams} / \mathrm{cm}^{2} / \mathrm{yr}=$ $-2.0 \% / \mathrm{yr}, n=28)$ were compared with those with more positive slopes $($ mean $=+0.3 \% / y r, n=68)($ Table $\mathrm{V})$. Those who lost $>1 \% / \mathrm{yr}$ from the femoral neck had serum $\mathrm{T}$ concentrations between $14 \%$ (total T, $0.05<P<0.10$ ) and $22 \%$ (free $\mathrm{T}, P<0.05)$ lower than those who did not lose bone from the hip (Table V). Those who lost bone also had slightly less weight gain than those who did not lose bone (+0.55 vs. 1.32 $\mathrm{kg} / \mathrm{yr}, 0.05<P<0.10)$. Changes in weight were not associated with sex steroids. There were no other differences between these two groups, nor did they differ in rates of change in bone density in the spine or radius. (Similar relationships were observed for older women. Serum total T concentrations were significantly [20\%] lower in those losing femoral neck bone density at $>1 \% / y r[n=55]$ compared with those with more positive slopes $[n=46]$, and those with greater bone loss gained less weight [data not shown].)

Multvariable associations with bone mass and bone loss. To test the independence of the predictors of bone mass and bone loss, models were constructed to predict: $(a)$ BMD at all sites (Table VI, left side); (b) changes in BMD at all sites (Table VI, right side); and (c) those who lost femoral neck BMD at a rate

Table III. Correlations with BMDs, by Menopausal Status

\begin{tabular}{|c|c|c|c|c|c|c|c|c|c|}
\hline \multirow[b]{2}{*}{$n=$} & \multicolumn{3}{|c|}{ Premenopausal } & \multicolumn{3}{|c|}{ Perimenopausal } & \multicolumn{3}{|c|}{ Postmenopausal } \\
\hline & $\begin{array}{c}\mathrm{FN} \\
92\end{array}$ & $\begin{array}{c}\mathrm{SP}^{*} \\
92\end{array}$ & $\begin{array}{l}\mathrm{R} \\
94\end{array}$ & $\begin{array}{c}\mathrm{FN} \\
28\end{array}$ & $\begin{array}{l}\text { SP } \\
28\end{array}$ & $\begin{array}{l}\mathrm{R} \\
62\end{array}$ & $\begin{array}{l}\mathrm{FN} \\
73\end{array}$ & $\begin{array}{l}\text { SP } \\
73\end{array}$ & $\begin{array}{l}\mathrm{R} \\
73\end{array}$ \\
\hline Age & 0.02 & 0.08 & -0.07 & $-0.34^{\ddagger}$ & $-0.46^{\S}$ & $-0.37^{\text {II }}$ & $-0.35^{\mathbb{I}}$ & -0.12 & $-0.37^{\text {II }}$ \\
\hline $\mathrm{Ht}$ & -0.01 & 0.07 & $0.42^{\mathbb{U}}$ & 0.11 & -0.04 & $0.40^{\text {II }}$ & 0.10 & 0.12 & 0.17 \\
\hline $\mathrm{Wt}$ & $0.46^{\pi}$ & $0.40^{\pi}$ & $0.24^{\S}$ & 0.14 & 0.04 & $0.40^{\text {q }}$ & $0.32^{\mathbb{I}}$ & $0.41^{\pi}$ & 0.18 \\
\hline Ch Wt & 0.12 & 0.07 & $0.23^{\S}$ & $0.32^{\ddagger}$ & 0.15 & $0.27^{\ddagger}$ & 0.03 & -0.11 & 0.02 \\
\hline FSH & -0.02 & 0.02 & -0.03 & -0.30 & -0.04 & $-0.35^{\text {II }}$ & -0.13 & -0.18 & 0.0 \\
\hline E1 & 0.04 & 0.08 & 0.02 & 0.14 & 0.13 & 0.07 & $0.24^{\S}$ & $0.32^{\text {II }}$ & 0.13 \\
\hline E2 & -0.10 & 0.01 & 0.09 & 0.21 & $0.49^{\pi}$ & $0.33^{\text {II }}$ & 0.16 & 0.06 & -0.03 \\
\hline $\mathrm{P}$ & -0.01 & 0.02 & -0.10 & 0.29 & 0.22 & -0.05 & 0.01 & -0.10 & 0.11 \\
\hline $\mathrm{T}$ & 0.02 & -0.02 & -0.01 & $0.44^{\pi}$ & $0.49^{\pi}$ & $0.25^{\S}$ & -0.01 & 0.02 & -0.04 \\
\hline NST $\|$ & 0.15 & 0.10 & -0.01 & $0.53^{\pi}$ & $0.50^{\pi}$ & $0.38^{\S}$ & 0.01 & 0.07 & 0.09 \\
\hline A & 0.03 & 0.05 & -0.01 & $0.42^{\S}$ & $0.52^{\mathbb{q}}$ & $0.25^{\S}$ & -0.09 & 0.01 & -0.11 \\
\hline SHBG & $-0.32^{\mathbb{\Psi}}$ & $-0.29^{\pi}$ & -0.02 & -0.09 & -0.02 & -0.01 & $-0.42^{\mathbb{I}}$ & $-0.32^{\mathbb{T}}$ & $-0.27^{\S}$ \\
\hline DHEA & -0.08 & -0.01 & 0.02 & $0.39^{\S}$ & $0.47^{\pi}$ & 0.13 & -0.10 & -0.14 & 0.02 \\
\hline DHEAS & 0.04 & 0.08 & 0.01 & $0.42^{\S}$ & $0.44^{\pi}$ & $0.28^{\S}$ & -0.07 & -0.02 & 0.10 \\
\hline $\mathrm{OC}$ & 0.12 & 0.08 & -0.16 & -0.14 & -0.27 & $-0.29^{\ddagger}$ & $-0.25^{\S}$ & -0.11 & $-0.32^{\mathbb{I}}$ \\
\hline
\end{tabular}

BMDs were the mean values over the entire period of study. Hormone and OC concentrations, height, weight, and age were also the mean values. Change in weight is the slope of body weight over time (i.e., the change in kg/yr). ${ }^{*} \mathrm{SP}=\mathrm{L} 2-\mathrm{L} 4 ;{ }^{*} 0.05<P<0.10 ;{ }^{\S} P<0.05 ;{ }^{\pi} P<0.01 ;$ and ${ }^{\|} \mathrm{NST}, \mathrm{T}$ not bound to SHBG. 
Table IV. Correlations with Changes in BMDs, by Menopausal Status

\begin{tabular}{|c|c|c|c|c|c|c|c|c|c|}
\hline \multirow[b]{2}{*}{$n=$} & \multicolumn{3}{|c|}{ Premenopausal } & \multicolumn{3}{|c|}{ Perimenopausal } & \multicolumn{3}{|c|}{ Postmenopausal } \\
\hline & $\begin{array}{l}\text { FN } \\
92\end{array}$ & $\begin{array}{l}\mathrm{SP}^{*} \\
92\end{array}$ & $\begin{array}{l}\mathrm{R} \\
94\end{array}$ & $\begin{array}{l}\text { FN } \\
28\end{array}$ & $\begin{array}{l}\text { SP } \\
28\end{array}$ & $\begin{array}{l}\mathrm{R} \\
62\end{array}$ & $\begin{array}{l}\mathrm{FN} \\
73\end{array}$ & $\begin{array}{l}\text { SP } \\
73\end{array}$ & $\begin{array}{c}\mathrm{R} \\
73\end{array}$ \\
\hline Age & 0.04 & 0.17 & 0.12 & -0.02 & -0.08 & -0.42 & 0.05 & 0.19 & $-0.37^{\ddagger}$ \\
\hline $\mathrm{Ht}$ & -0.14 & -0.03 & 0.05 & -0.03 & -0.04 & 0.10 & 0.15 & -0.06 & -0.02 \\
\hline Wt & -0.03 & -0.05 & 0.02 & -0.08 & -0.13 & -0.11 & 0.10 & -0.07 & 0.13 \\
\hline Ch Wt & 0.01 & 0.04 & $0.19^{\S}$ & 0.17 & 0.09 & -0.14 & $0.51^{\ddagger}$ & 0.02 & -0.14 \\
\hline FSH & 0.01 & 0.13 & 0.09 & -0.11 & -0.27 & $-0.38^{\ddagger}$ & 0.18 & 0.02 & 0.01 \\
\hline E1 & 0.02 & 0.10 & 0.14 & 0.08 & 0.14 & -0.03 & 0.04 & $0.35^{\ddagger}$ & 0.07 \\
\hline E2 & 0.01 & 0.06 & 0.08 & 0.17 & 0.07 & $+0.23^{\S}$ & -0.02 & 0.18 & $0.24^{\pi}$ \\
\hline $\mathrm{P}$ & -0.09 & 0.04 & -0.04 & 0.07 & 0.20 & 0.05 & 0.12 & $0.28^{\pi}$ & -0.11 \\
\hline $\mathrm{T}$ & 0.16 & 0.05 & -0.16 & 0.07 & 0.12 & $0.35^{\ddagger}$ & 0.16 & $0.22^{\S}$ & 0.13 \\
\hline $\mathrm{NST}^{\|}$ & 0.16 & 0.05 & $-0.20^{\S}$ & 0.0 & -0.02 & $0.32^{\ddagger}$ & $0.24^{\pi}$ & $0.20^{\pi}$ & 0.04 \\
\hline A & 0.09 & -0.11 & -0.01 & -0.16 & -0.08 & $0.44^{\ddagger}$ & 0.16 & 0.07 & 0.17 \\
\hline SHBG & $-0.06^{\mathbb{T}}$ & 0.05 & 0.11 & 0.23 & 0.31 & 0.02 & $-0.23^{\mathbb{I}}$ & -0.16 & -0.08 \\
\hline DHEA & $0.21^{\pi}$ & -0.13 & -0.08 & -0.03 & -0.01 & 0.16 & 0.17 & 0.05 & -0.02 \\
\hline DHEAS & $0.21^{\text {II }}$ & 0.01 & -0.15 & 0.18 & 0.07 & $0.30^{\text {I }}$ & 0.09 & 0.10 & 0.03 \\
\hline $\mathrm{OC}$ & -0.09 & -0.15 & -0.04 & -0.04 & -0.18 & $-0.51^{\ddagger}$ & 0.03 & 0.01 & $-0.32^{\ddagger}$ \\
\hline
\end{tabular}

Changes in BMD are the within-subject slopes calculated in grams $/ \mathrm{cm}^{2} / \mathrm{yr}$. Hormone concentrations, OC, height, weight, and age are mean values calculated over the entire period of study. Change in weight is the slope of body weight over time (i.e., change in weight in $\mathrm{kg} / \mathrm{yr}$ ). ${ }^{* \mathrm{SP}}=\mathrm{L} 2-\mathrm{L} 4 ;{ }^{\circledR} 0.05<$ $P<0.10 ;{ }^{\pi} P<0.05 ;{ }^{\ddagger} P<0.01$; and ${ }^{\|}$NST, T not bound to SHBG.

of $1 \% / y r$ or greater (Table VII). Among the variables related to sex steroids, only SHBG consistently predicted BMD, although both $\mathrm{T}$ and E2 were associated positively with BMDs in perimenopausal women. Weight, age, and SHBG together

Table V. Premenopausal Women Only

\begin{tabular}{|c|c|c|}
\hline \multicolumn{3}{|l|}{ FN change } \\
\hline & $<-1 \%$ & $>-1 \%$ \\
\hline & $n=28$ & $n=68$ \\
\hline Age (yr) & 41.7 & 41.7 \\
\hline \multicolumn{3}{|c|}{ BMD change (grams $\left./ \mathrm{cm}^{2} / \mathrm{yr}\right)$} \\
\hline FN & -0.017 & $+0.003^{*}$ \\
\hline Trochanter & -0.006 & $+0.001^{\ddagger}$ \\
\hline Spine & +0.003 & +0.004 \\
\hline FSH (mIU/liter) & 8.8 & 8.7 \\
\hline Wt change $(\mathrm{kg} / \mathrm{yr})$ & +0.55 & $+1.32^{\S}$ \\
\hline Weight $(\mathrm{kg} / \mathrm{yr})$ & 65.8 & 68.2 \\
\hline Height $(\mathrm{cm})$ & 163 & 165 \\
\hline $\mathrm{E} 1(\mathrm{pg} / \mathrm{ml})$ & 45.6 & 47.9 \\
\hline $\mathrm{E} 2(\mathrm{pg} / \mathrm{ml})$ & 47.5 & 47.5 \\
\hline $\mathrm{P}$ & 0.19 & 0.16 \\
\hline $\mathrm{T}(\mathrm{ng} / \mathrm{ml})$ & 0.20 & $0.23^{\S}$ \\
\hline $\operatorname{NST}(\mathrm{ng} / \mathrm{ml})^{\mathbb{\pi}}$ & 0.066 & $0.079^{\S}$ \\
\hline FrT (ng/ml) & 0.0033 & $0.0042^{\|}$ \\
\hline $\mathrm{A}(\mathrm{ng} / \mathrm{ml})$ & 1.05 & 1.17 \\
\hline DHEA (ng/ml) & 2.07 & 2.26 \\
\hline DHEAS $(\mu \mathrm{g} / \mathrm{ml})$ & 1.46 & 1.67 \\
\hline SHBG (nM/liter) & 63.4 & 63.1 \\
\hline $\mathrm{OC}(\mathrm{ng} / \mathrm{ml})$ & 9.9 & 9.1 \\
\hline
\end{tabular}

IT not bound to SHBG; * Statistical significance not tested, defined as no overlap; ${ }^{\S} 0.05<P<0.10 ; " P<0.05$; and ${ }^{\ddagger} P<0.01$. accounted for between 37 (SP) and 47\% (FN) of the variability in BMD when all women were combined (data not shown).

Serum $\mathrm{T}$ concentrations were lower among those losing femoral neck BMD more rapidly (Table VII), and the effect size (i.e., regression coefficient) is approximately the same in all three groups. Consistent with the logistic regression analysis, $\mathrm{T}$ concentrations predicted rates of premenopausal bone loss from the femoral neck $(P=0.076)$, in models which also contained weight, age, and E2. Both E2 and T concentrations were associated with slower bone loss from the radius in perimenopausal women (confirming our previous study results [7]). In older postmenopausal women, depending on skeletal site, both higher $\mathrm{T}$ and estrogen concentrations were associated with slower bone loss.

\section{Discussion}

Bone loss. The role of sex steroids in the maintenance of the female skeleton is clear only in narrow circumstances. Estrogen deficiency drives menopausal bone loss and can be used therapeutically to prevent such loss $(1,2)$. Estrogen deficiency also plays a primary role in the bone loss associated with menstrual disturbances in young women (3-6), although there may be circumstances where the detrimental skeletal effects of estrogen deficiency can be avoided (8-11). In the healthy, normally cycling women recruited for the current study, after 3-5 yr of follow-up, there was evidence of premenopausal bone loss only from the hip. This magnitude of this loss, $3 \%$ per decade, is consistent with recent cross-sectional data from the NHANES III (16) as well as with the databases of the manufacturers of densitometers. Taken together, these multiple sources of data suggest that bone loss from the proximal femur occurs before menopause, but further prospective studies to examine the issue of premenopausal bone loss are needed. Although this is a modest rate of bone loss, over the three de- 
Table VI. Multivariable Regression Models for BMD and Changes in BMD

\begin{tabular}{|c|c|c|c|}
\hline $\begin{array}{l}\text { Dependent variable } \\
\text { Independent variables } \\
\text { entered* }\end{array}$ & $\begin{array}{l}\text { BMD } \\
\text { SHBG, Ht, Wt, E1, E2, } \\
\text { and unbound T }\end{array}$ & $\begin{array}{c}\text { Change in BMD } \\
\text { Each included E1 or E2, } \\
\text { T or unbound } \mathrm{T}, \mathrm{Wt}, \mathrm{Ch} \text {. in } \mathrm{Wt} \text {, and Age }\end{array}$ & \\
\hline$\underline{\text { Predictors (coefficient } \pm \text { SE) }}$ & Significance & $\underline{\text { Predictors (coefficient } \pm \text { SE) }}$ & $\underline{\text { Significance }}$ \\
\hline \multicolumn{4}{|l|}{ Premenopausal } \\
\hline $\begin{array}{l}F N B M D= \\
\quad \text { SHBG }(-0.0014 \pm 0.0006) \\
\quad \text { Wt }(0.0032 \pm 0.0010)\end{array}$ & $\begin{array}{l}0.02 \\
0.002\end{array}$ & $\begin{array}{l}\text { Change in } F N B M D= \\
\quad \text { Unbound } \mathrm{T}(0.078 \pm 0.44)\end{array}$ & 0.076 \\
\hline & $\mathrm{R}^{2}=24.9 \%$ & & $\mathrm{R}^{2}=7 \%$ \\
\hline $\begin{array}{l}S P B M D= \\
\quad \text { SHBG }(-0.0022 \pm 0.0007) \\
\text { Wt }(0.0029 \pm 0.0011)\end{array}$ & $\begin{aligned} & 0.002 \\
& 0.01 \\
\mathrm{R}^{2}= & 25.6 \%\end{aligned}$ & $\begin{array}{l}\text { Change in } S P B M D= \\
\text { None }\end{array}$ & \\
\hline $\begin{array}{l}\text { Mid-radius } B M D= \\
\text { Wt }(0.0007 \pm 0.00035) \\
\text { Ht }(0.0028 \pm 0.0008)\end{array}$ & $\begin{array}{l}0.058 \\
0.0004\end{array}$ & $\begin{array}{l}\text { Change in mid-radius } B M D= \\
\quad \mathrm{E} 1(0.0072 \pm 0.0041)\end{array}$ & 0.085 \\
\hline & $\mathrm{R}^{2}=20.4 \%$ & & $\mathrm{R}^{2}=6 \%$ \\
\hline \multicolumn{4}{|l|}{ Perimenopausal } \\
\hline $\begin{array}{l}F N B M D= \\
\quad \text { Unbound T }(1.64 \pm 0.58)\end{array}$ & $\begin{array}{c}0.01 \\
\mathrm{R}^{2}=35.2 \%\end{array}$ & $\begin{array}{l}\text { Change in FN BMD = } \\
\text { None }\end{array}$ & \\
\hline $\begin{array}{l}S P B M D= \\
\quad \text { Unbound T }(1.91 \pm 0.65) \\
\quad \mathrm{E} 2(0.20 \pm 0.08)\end{array}$ & $\begin{aligned} & 0.008 \\
& 0.02 \\
\mathrm{R}^{2}= & 47.7 \%\end{aligned}$ & $\begin{array}{l}\text { Change in SP BMD = } \\
\text { None }\end{array}$ & \\
\hline $\begin{array}{l}\text { Mid-radius } B M D= \\
\text { Wt }(0.0021 \pm 0.0011) \\
\text { E2 }(0.083 \pm 0.033)\end{array}$ & $\begin{array}{c}0.07 \\
0.02 \\
\mathrm{R}^{2}=43.8 \%\end{array}$ & $\begin{array}{l}\text { Change in mid-radius } B M D= \\
\text { Unbound } \mathrm{T}(0.065 \pm 0.031) \\
\text { E2 }(0.0093 \pm 0.0037)\end{array}$ & $\begin{array}{c}0.047 \\
0.02 \\
\mathrm{R}^{2}=42 \%\end{array}$ \\
\hline \multicolumn{4}{|l|}{ Postmenopausal } \\
\hline $\begin{array}{l}F N B M D= \\
\quad \text { SHBG }(-0.0018 \pm 0.0007)\end{array}$ & 0.008 & $\begin{array}{l}\text { Change in FN BMD }= \\
\text { Ch in Wt }(0.0033 \pm 0.0007) \\
\text { Unbound } \mathrm{T}(0.057 \pm 0.028)\end{array}$ & $\begin{array}{l}0.001 \\
0.045\end{array}$ \\
\hline & $\mathrm{R}^{2}=23.1 \%$ & & $\mathrm{R}^{2}=28.5 \%$ \\
\hline $\begin{array}{l}S P B M D= \\
\quad \mathrm{Wt}(0.0038 \pm 0.0018)\end{array}$ & 0.04 & $\begin{array}{l}\text { Change in SP BMD = } \\
\text { Wt }(-0.00035 \pm 0.00018) \\
\text { E1 }(0.021 \pm 0.008)\end{array}$ & $\begin{array}{l}0.057 \\
0.01\end{array}$ \\
\hline & $\mathrm{R}^{2}=22.5 \%$ & & $\mathrm{R}^{2}=18 \%$ \\
\hline $\begin{array}{l}\text { Mid-radius } B M D= \\
\quad \text { SHBG }(-0.0013 \pm 0.0006)\end{array}$ & 0.02 & $\begin{array}{l}\text { Change in mid-radius } B M D= \\
\text { E2 }(0.0067 \pm 0.0037) \\
\text { Age }(0.0006 \pm 0.0002)\end{array}$ & $\begin{array}{l}0.07 \\
0.001\end{array}$ \\
\hline & $\mathrm{R}^{2}=13.3 \%$ & & $\mathrm{R}^{2}=19 \%$ \\
\hline
\end{tabular}

*Units are as indicated in previous tables.

cades between the end of femoral neck bone acquisition (about age 15-20) and menopause there would be approximately a $1 \mathrm{SD}$ decline in BMD, and thus, a corresponding twoto threefold increase in risk of femoral neck fracture (17).

This loss was weakly associated with lower androgen concentrations and reduced weight gains, but these accounted for only a small fraction of the variability in rates of change in the femoral neck, suggesting that these are only minor determinants of changes in the skeleton of premenopausal women, and there must be other more important determinants of premenopausal bone loss from the femoral neck. It is possible that the decline in physical activity common in early adult life plays a role, but a more intensive study of exercise patterns would be needed to address this. It should also be noted that the mea- surements of sex steroids in this study were all made in the early follicular phase of the menstrual cycle, and therefore may not adequately represent sex steroid concentrations for premenopausal women throughout the menstrual cycle, particularly with respect to the estrogens and progesterone. It is possible that multiple blood samples over the course of the menstrual cycle may be necessary to adequately characterize the associations between estrogens and skeletal health in premenopausal women. It should also be noted that there were significantly positive slopes for the changes in bone mass in the spine and radius of premenopausal women, although there is little independent support for gains in BMD at these sites beyond ages 25-30. Because all of these rates of change in BMD are small, caution in interpretation is required. However, the 
Table VII. Logistic Regression Models

Dependent variable-FN bone loss $>1 \% / \mathrm{yr}$

Independent variables entered-SHBG, E2, T, Change in Wt., and Age*

\begin{tabular}{llllc}
\hline & \multicolumn{2}{c}{ Predictors (coefficient \pm SE) } & & Significance \\
\cline { 2 - 3 } Premenopausal & $\mathrm{T}$ & $(-0.98 \pm 0.58)$ & & 0.09 \\
Perimenopausal & $\mathrm{T}$ & $(-1.11 \pm 0.82)$ & 0.17 \\
Postmenopausal & $\mathrm{T}$ & $(-0.97 \pm 0.49)$ & & 0.049 \\
& Change in Wt. & $(-0.38 \pm 0.19)$ & \\
& & & 0.049 \\
\hline
\end{tabular}

*Units areas are as indicated in previous tables.

potential importance of premenopausal bone loss from the proximal femur, if confirmed, is great, given the implications for increasing fracture risk.

In perimenopausal women both testosterone and estrogen concentrations were lower in those losing radial bone mass at greater rates, consistent with our previous observations in a slightly larger group of women (7), both in terms of the magnitude of the effect and the statistical significance of the predictors. Also consistent with our previous observations, serum osteocalcin concentrations were greater in those with greater declines in radius BMD, reflecting the increased skeletal turnover associated with menopausal declines in estrogen concentrations. There were no significant predictors of changes in BMD at the spine or hip in perimenopausal women, but this was quite a small sample of women $(n=28)$ because of limitations in the bone mass measurements. In addition, declines in sex steroid concentrations were not associated with declines in BMD (i.e., identification of a rate of change in sex steroids which triggered bone loss was not possible).

In older postmenopausal women (age $>60 \mathrm{yr}$ ), as with women closer to menopause, estrogen concentrations were higher among those losing bone mass at slower rates from the spine and radius. Testosterone concentrations were associated with bone loss only from the hip. Increasing body weight also provided some protection against bone loss from the hip, as it did in premenopausal women. In older women, however, the effect was stronger, with each 5-lb gain in weight associated with a $1 \% / y r$ slower rate of femoral neck bone loss. Long-term weight gain has been associated recently with a reduced risk of femoral neck fracture (18), and it is plausible that slower rates of bone loss from the hip provide some fracture protection, independent of the beneficial effect of higher bone mass, perhaps through the preservation of the trabecular structure of the femur.

Bone mass. In addition to age, weight and SHBG were strong independent predictors of BMD. These three variables together accounted for nearly half of the variability in BMD in the radius and hip, and $37 \%$ of that in the lumbar spine. The role of SHBG in the determination of BMD is uncertain. This association is present before bone loss has begun, as has been reported previously (12) and changes little with advancing age, and, thus, may reflect processes that occurred during growth and which are simply maintained through the rest of life. Although the precise role of sex steroids in bone growth during puberty is not well understood, there is little doubt that diminished availability of sex steroids at this time is detrimental (3, 6 ), and the presence of high concentrations of SHBG at this stage of life might contribute to smaller peak adult bone mass. Although it is probable that the SHBG/BMD association is in- direct, reflecting either the biological activity of sex steroids or some other intermediate variable, further exploration of this concept is needed.

If SHBG diminishes peak bone mass through indirect effects mediated by lowered concentrations of sex steroids, these effects are more likely caused by diminished androgens rather than estrogens, because premenopausal women with higher SHBG concentrations have higher concentrations of both total and free E2, in contrast to the negative association between SHBG and unbound $\mathrm{T}$ in this group. Only studies in growing children can address this directly.

Summary. In multiple analyses of bone density and bone loss across a broad spectrum of age, both estrogen and androgens appear to play important roles in skeletal health. However, for premenopausal bone loss these effects are confined to androgens and are relatively small. In the perimenopausal period and later, estrogens and androgens act independently to slow bone loss. SHBG is consistently associated negatively with BMD, but not with bone loss. The mechanism of this effect is unknown and may reflect processes occurring earlier in life. Together, SHBG and the sex steroids account for a substantial proportion of the variance in BMD and a smaller proportion of the variance in bone loss. The effects of both estrogens and androgens on bone loss are mainly confined to estrogen-deficient women.

\section{References}

1. Albright, F., P. H. Smith, and A. M. Richardson. 1941. Postmenopausal osteoporosis-its clinical features. JAMA (J. Am. Med Assoc.). 116:2465-2473.

2. Lindsay, R., D. M. Hart, C. Forrest, and C. Baird. 1980. Prevention of spinal osteoporosis in oophorectomized women. Lancet. 2:1151-1154.

3. Drinkwater, B. L., B. Breumner, and C. Chestnut. 1990. Menstrual history as a determinant of current bone density in athletes. JAMA (J. Am. Med. Assoc.). 263:545-548.

4. Crosby, L. O., F. S. Kaplan, M. J. Pertschuk, and J. L. Mullen. 1985. The effect of anorexia nervosa on bone morphometry in young women. Clin. Orthop. 201:271-277.

5. Fisher, E. C., M. E. Nelson, W.R. Frontera, R. N. Turksoy, and W. J. Evans. 1986. Bone mineral content and levels of gonadotropins and estrogens in amenorrheic running women. J. Clin. Endocrinol. \& Metab. 62:1232-1236.

6. Armamento-Villereal, R., D. T. Villereal, L. Avioli, and R. Civitelli. 1992. Estrogen status and heredity are major determinants of premenopausal bone mass. J. Clin. Invest. 90:2464-2471.

7. Slemenda, C. W., S. L. Hui, C. L. Longcope, and C. C. Johnston. 1987. Sex steroids and bone mass. A study of changes about the time of menopause. J. Clin. Invest. 80:1261-1269.

8. Buchanan, J. R., P. Hospodar, C. Myers, P. Leuenberger, and L. Demers. 1988. Effect of excess androgens on bone density in young women. J. Clin. Endocrinol. \& Metab. 67:937-943.

9. Slemenda, C. W., and C. C. Johnston. 1993. High intensity activities in young women: site specific bone mass effects among figure skaters. Bone Miner. 20:125-132.

10. Robinson, T. L., C. Snow-Harter, D. R. Taaffe, D. Gillis, J. Shaw, and R. Marcus. 1995. Gymnasts exhibit higher bone mass than runners despite similar prevalence of amenorrhea and oligomenorrhea. J. Bone Miner. Res. 10:2635 .

11. Dixon, J. E., A. Rodin, B. Murby, M. G. Chapman, and I. Fogelman. 1989. Bone mass in hirsute women with androgen excess. Clin. Endocrinol. 30: 271-277.

12. Steinberg, K. K., L. W. Freni-Titulaer, E. G. DePuey, D. T. Miller, D. S. Sgoutas, C. H. Coralli, D. L. Phillips, T. N. Rogers, and R. V. Clark. 1989. Sex steroids and bone density in premenopausal and perimenopausal women. $J$. Clin. Endocrinol. \& Metab. 69:533-539.

13. Sowers, M. F. R., M. K. Clark, B. Hollis, R. B. Wallace, and M. Jannusch. 1992. Radial bone mineral density in pre- and perimenopausal women: a prospective study of rates and risk factors for loss. J. Bone Miner. Res. 7:647657.

14. Cauley, J. A., J. P. Gutai, R. B. Sandler, R. E. LaPorte, L. H. Kuller, and D. Sashin. 1986. The relationship of endogenous estrogen to bone density and bone area in normal postmenopausal women. Am. J. Epidemiol. 124:752-761.

15. vanHermert, A. M., J. C. Birkenhager, F. H. DeJong, J. P. Vandenbroucke, and H. A. Valkenburg. 1989. Sex hormone binding globulin in post- 
menopausal women: a predictor of osteoporosis superior to endogenous oestrogens. Clin. Endocrinol. 31:499-509.

16. Looker, A. C., C. C. Johnston, H. W. Wahner, W. L. Dunn, M. S. Calvo, T. B. Harris, S. P. Heyse, and R. L. Lindsay. 1995. Prevalence of low femoral bone density in older U.S. women from NHANES III. J. Bone Miner. Res. 10: 796-802.

17. Cummings, S. R., D. M. Black, M. C. Nevitt, W. Browner, J. Cauley, K.
Ensrud, H. K. Genant, C. C. Gluer, S. B. Hulley, L. Palermo, J. Scott, T. M. Vogt, and the Study of Osteoporotic Fractures Research Group. 1993. Bone density at various sites for the prediction of hip fractures. Lancet. 341:72-75.

18. Cummings, S. R., M. C. Nevitt, W. S. Browner, K. Stone, K. M. Fox, K. E. Ensrud, J. Cauley, D. Black, and T. M. Vogt. 1995. Risk factors for hip fracture in white women. N. Engl. J. Med. 332:767-773. 